\title{
Associação de agenesia sacrococcígea e atresia anal em gato sem raça definida
}

\author{
Sacrococcygeal agenesis association and anal atresia in mixed breed cats \\ Felipe Purcell de Araújo ${ }^{I}$ Bruno Martins Araújo ${ }^{I I}$ Bernardo Kemper ${ }^{I I I}$ \\ Eduardo Alberto Tudury ${ }^{\mathrm{IV}}$
}

\begin{abstract}
- NOTA -
RESUMO

O presente trabalho teve como objetivo descrever o caso de um felino, que desde o nascimento apresentou atresia anal, ausência de cauda e malformação dos membros pélvicos. Ao exame radiográfico, pôde-se observar presença de agenesia da sétima vértebra lombar, sacro e vértebras coccígeas, espinha bífida, meningocele, hiperflexão dos joelhos e desvio valgo dos tarsos, diagnosticando-se agenesia sacrococcígea associada à atresia anal.

Palavras-chave: Agenesia, região sacrococcígea, atresia anal, gatos.

\section{ABSTRACT}

This paper has the objective to report a case of a cat that since birth had anal atresia, absence of tail and malformation of the pelvic member. The radiographic examination revealed agenesis of the seventh lumbar vertebra, sacral and coccygeal vertebrae, spina bifida, meningocele, hyperflexion of the knees and tarsal valgus deviation, diagnosing sacrococcygeal agenesis associated with anal atresia.

Key words: Agenesis, sacrococcygeal region, anal atresia, cats.

Agenesia sacrococcígea constitui um conjunto de anormalidades congênitas que envolvem

as estruturas ósseas e os tecidos moles adjacentes à coluna vertebral lombossacra e coccígea de cães e gatos (CHRISMAN, 1991; COATS, 2004). É um achado frequente em gatos Manx (LECOUTEUR \& GRANDY, 2004; CHRISMAN et al., 2005; DEWEY, 2006) e ocasional em outras espécies (CHRISMAN, 1991).

Os sinais clínicos manifestam-se logo após o nascimento e dependem da gravidade das malformações da coluna vertebral, medula espinhal e da cauda equina (CHRISMAN et al., 2005), podendo ser estáveis ou progressivos (LECOUTEUR \& GRANDY, 2004; LORENZ \& KORNEGAY, 2004; DEWEY, 2006). As lesões caudais ao sexto segmento lombar $\left(\mathrm{L}_{6}\right)$ da medula espinhal comprometem as raízes nervosas que contribuem para a formação dos nervos pélvicos, pudendos, isquiáticos e caudais, promovendo disfunções dos neurônios motores inferiores viscerais e dos membros pélvicos (MACIEL et al., 2002; COATS, 2004; LORENZ \& KORNEGAY, 2004).

O diagnóstico baseia-se nos sinais clínicos e radiográficos que indicam agenesia das vértebras sacrais e coccígeas (DEWEY, 2006). Pode-se observar agenesia sacrococcígea em radiografias simples, e a mielografia pode indicar malformação nas meninges (LECOUTEUR \& GRANDY, 2004; CHRISMAN et al., 2005).
\end{abstract}

\footnotetext{
'Programa de Pós-graduação em Ciência Veterinária, Departamento de Medicina Veterinária (DMV), Universidade Federal Rural de Pernambuco (UFRPE), Recife, PE, Brasil.

"Residente de Cirurgia de Pequenos Animais, Hospital Veterinário, DMV, UFRPE. E-mail: bmaraujo85@hotmail.com. Endereço para correspondência: Rua Henrique Dias, nº5, 53403-485, Vila Torres Galvão, Paulista, PE, Brasil.

IIIUniversidade Norte do Paraná (UNOPAR), Londrina, PR, Brasil.

${ }^{\mathrm{IV}}$ DMV, UFRPE, Recife, PE, Brasil.
} 
A frequente inexistência de estruturas anatômicas para a inervação do ânus e da bexiga urinária determina a impossibilidade de qualquer tratamento (DEWEY, 2006). Nesses casos, os animais podem ser mantidos a partir de esvaziamento manual da bexiga urinária e da administração de emolientes fecais (CHRISMAN, 1991; LORENZ \& KORNEGAY, 2004).

Este trabalho foi desenvolvido com o objetivo de relatar a associação de agenesia sacrococcígea e atresia anal em um gato sem raça definida, fêmea, dois meses de idade, pesando 600 gramas, encaminhado para o Hospital Veterinário da Universidade Federal Rural de Pernambuco (UFRPE), por apresentar desde o nascimento atresia anal, ausência de cauda e alteração dos membros pélvicos (Figura 1). Segundo a proprietária, o animal nasceu de uma ninhada de outros três filhotes e pais normais. Também informou que não houve progressão do quadro clínico desde o nascimento.
No exame clínico, foi observada atresia anal com presença de fistula reto-vaginal, abdome distendido decorrente de bexiga urinária repleta e retenção fecal; alteração dos membros pélvicos com hiperflexão dos joelhos que impossibilitava a extensão dos membros e presença de severa atrofia muscular; malformação da coluna vertebral, com ausência de cauda; alteração perceptível na fusão dos arcos vertebrais dorsais durante palpação das últimas vértebras lombares, com formação subcutânea de cisto e aparente agenesia do sacro. No exame neurológico, não foram detectadas alterações de nervos cranianos e dos membros torácicos. Nos membros pélvicos, foram observadas paraplegia e ausência de nocicepção. Em relação aos reflexos espinhais, devido à hiperflexão dos joelhos e contratura do quadríceps, não foi possível avaliar o reflexo patelar, mas o animal apresentava reflexo flexor diminuído e ausência do reflexo perineal, caracterizando uma síndrome lombossacra simétrica grave.

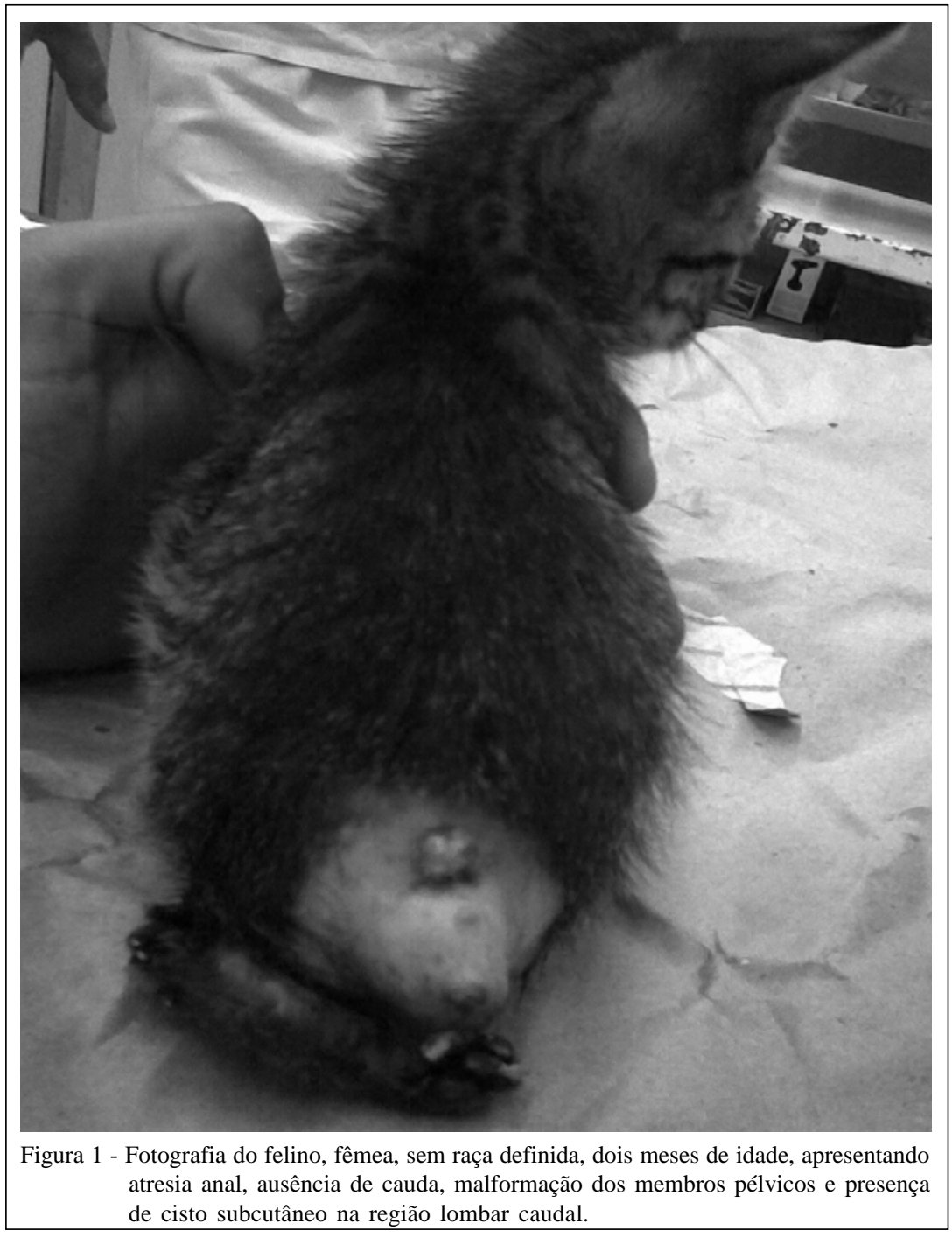

Ciência Rural, v.39, n.6, set, 2009. 
Um dia após o atendimento, realizou-se procedimento cirúrgico para correção da atresia anal. Uma semana após o procedimento, foram realizados exame radiográfico simples, punção do cisto subcutâneo e mielografia da região lombossacra.

No exame radiográfico, foram observados agenesia da vértebra $L_{7}$, sacro e vértebras coccígeas, ausência de fusão dos arcos vertebrais de $L_{5}$ e $L_{6}$ (espinha bífida), malformação de corpo vertebral de $\mathrm{L}_{6}$, hiperflexão dos joelhos, desvio valgo dos tarsos e retenção fecal (Figura 2-A). Na punção subcutânea do cisto, foram drenados aproximadamente $0,5 \mathrm{ml}$ (10 gotas) de líquido cefalorraquidiano de cor e aspecto característicos, sendo por ali injetados $0,18 \mathrm{ml}$ de Ioversol $\left(0,3 \mathrm{ml} \mathrm{kg}^{-1}\right)$ para realização da mielografia, que confirmou a presença de meningocele (Figura 2-B). Diante dos achados clínicos e exames complementares, foi possível obter o diagnóstico de atresia anal e agenesia sacrococcígea.

O diagnóstico de agenesia sacrococcígea foi obtido por meio dos sinais clínicos e exames radiográficos que indicaram agenesia das vértebras sacrais e coccígeas, concordando com LECOUTEUR e GRANDY (2004), DEWEY (2006). Segundo COATS (2004) e CHRISMAN et al. (2005), espinha bífida e meningocele são alterações constantemente associadas à agenesia sacrococcígea, estando tais alterações presentes nesse animal. Na literatura consultada, não foi verificado relato de atresia anal associada à agenesia sacrococcígea, sendo este considerado um caso raro.

Por meio do exame radiográfico, foram confirmadas as alterações da coluna vertebral. Na mielografia, observou-se alteração das meninges, concordando com DEFOREST \& BASRUR (1979), LECOUTEUR \& GRANDY (2004) e CHRISMAN et al. (2005). Pela falta de recursos (ressonância magnética), não foi possível realizar exames detalhados para verificação da integridade da medula espinhal e cauda equina.

Devido à ausência de inervação para a bexiga urinária e para o ânus, não havendo, dessa forma qualquer possibilidade de tratamento corretivo (CHRISMAN et al., 2005), foi recomendado o tratamento de suporte com esvaziamento vesical manual quatro vezes ao dia, evitando infecções vesicais e/ou assaduras e fornecimento de dieta apropriada, bem como retornos periódicos ao hospital, na evidência de qualquer alteração neurológica, seguindo as recomendações de CHRISMAN (1991), LECOUTEUR \& GRANDY (2004) e CHRISMAN et al. (2005). Foi preconizada também fisioterapia passiva para fortalecimento da musculatura dos membros pélvicos.

A retenção fecal ocorreu secundariamente à atresia anal, sendo necessário tratamento cirúrgico para resolução do problema. O procedimento cirúrgico
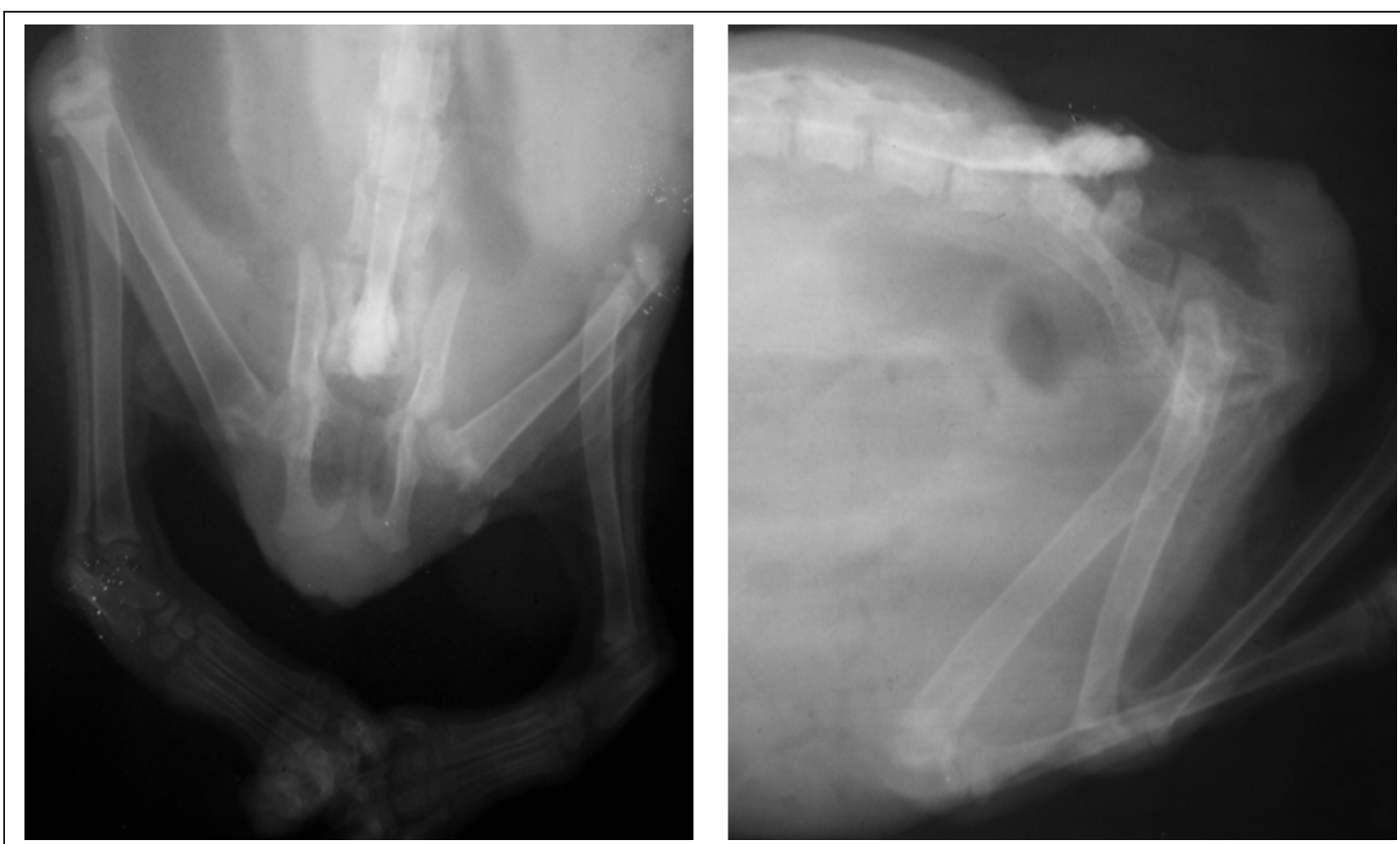

Figura 2 - Imagens radiográficas nas projeções ventro-dorsal (A) e lateral (B), demonstrando agenesia da sétima vértebra lombar, vértebras sacrais e coccígeas, ausência de fusão dos arcos vertebrais da quinta a sexta vértebras lombares, malformação de corpo da sexta vértebra lombar, hiperflexão dos joelhos, desvio valgo dos tarsos, retenção fecal e meningocele. 
possibilitou o esvaziamento do intestino. Contudo, a existência da anormalidade neurológica resultou em incontinência fecal, que foi manejada de forma conservativa com limpeza diária e dieta apropriada.

Mesmo com o prognóstico desfavorável, o proprietário optou em manter o animal vivo, sendo necessárias adaptações da terapia com o desenvolvimento corporal e monitoração constante deste para detectar alterações decorrentes das malformações, pois, de acordo com CHRISMAN et al. (2005) e DEWEY (2006), as alterações neurológicas causadas por malformações vertebrais podem piorar à medida que o animal cresce, como resultado de aumento da compressão ou do comprometimento da medula espinhal .

Segundo BRAUND (1994), condições mielodisplásicas podem estar associadas à espinha bífida, o que torna o prognóstico desfavorável. Como as mielodisplasias são identificadas à histopatologia (LECOUTEUR \& GRANDY, 2004), não foi possível identificar a possível ocorrência desse tipo de alteração na medula espinhal do animal.

\section{CONCLUSÃO}

Agenesia sacrococcígea é uma alteração nunca antes relatada em associação com atresia anal. Neste animal, o diagnóstico pôde ser obtido por meio de exames clínicos e radiográficos. O procedimento cirúrgico da região anal possibilitou a eliminação das fezes, mas as alterações neurológicas resultantes das malformações ósseas, espinhais e da cauda equina resultaram em incontinência fecal e disfunções dos membros pélvicos permanentes.

\section{REFERÊNCIAS}

BRAUND, K.G. Clinical syndromes in veterinary neurology. 2.ed. St. Louis, 1994. 476p.

CHRISMAN, C.L. Bladder distention, dilated anus, and atonic tail. In: _____. Problems in small animal neurology. 2.ed. Philadelphia: Lea \& Febiger, 1991. Cap.19, p.451-268.

CHRISMAN, C. et al. Flacidez caudal, anal e vesical. In: Neurologia para os clínicos de pequenos animais. São Paulo: Roca, 2005. Cap.15, p.315-324.

COATS, J.R. Tail, anal and bladder dysfunctions. In: PLATT, S.R.; OLBY, N.J. BSAVA Manual canine and feline neurology. 3.ed. London: BSAVA, 2004. Cap.18, p.302336 .

DEFOREST, M.E.; BASRUR, P.K. Malformations and the Manx syndrome in cats. Canadian Veterinary Journal. v.20, p.304-314, 1979.

DEWEY, W. Doenças da cauda eqüina. In: Neurologia de cães e gatos. Guia prático. São Paulo: Roca, 2006. Cap.10, p.197-207.

LECOUTEUR, R.A.; GRANDY, J.L. Doenças da medula espinhal. In: ETTINGER, S. J. ;FELDMAN, E.C. Tratado de medicina interna veterinária: moléstias do cão e do gato. 5.ed. Rio de Janeiro: Gunanabara Koogan, 2004. V.1, cap. 06, p.664-694.

LORENZ, M.D.; KORNEGAY, J.N. Pelvic limbs paresis, paralysis, or ataxia. In: ____ Handbook of veterinary neurology. 4.ed. St. Louis: Saunders, 2004. Cap.6, p.131174 .

MACIEL, M.J.S. et al. Disgenesia sacrococcígea em cão relato de caso. In: JORNADA DE ENSINO, PESQUISA E EXTENSÃO - JEPEX, 2., 2002, Recife-PE. Anais... Recife: UFRPE, 2002. p.101-102. 